\title{
VERIFICATION OF STRENGTH OF THE WELDED JOINTS BY USING OF THE ARAMIS VIDEO SYSTEM
}

\author{
Tadeusz PAŁA*, Ihor DZIOBA*, Jarosław GAŁKIEWICZ \\ *Department of Machine Design Fundamentals, Faculty of Mechatronics and Machine Design, Kielce University of Technology, \\ Al. 1000-lecia PP 7, 25-314 Kielce, Poland \\ tadeusz.pala@gmail.com, pkmid@tu.kielce.pl, jgalka@tu.kielce.pl
}

received 8 October 2015, revised 22 February 2017, accepted 6 March 2017

\begin{abstract}
In the paper are presented the results of strength analysis for the two types of the welded joints made according to conventional and laser technologies of high-strength steel S960QC. The hardness distributions, tensile properties and fracture toughness were determined for the weld material and heat affect zone material for both types of the welded joints. Tests results shown on advantage the laser welded joints in comparison to the convention ones. Tensile properties and fracture toughness in all areas of the laser joints have a higher level than in the conventional one. The heat affect zone of the conventional welded joints is a weakness area, where the tensile properties are lower in comparison to the base material. Verification of the tensile tests, which carried out by using the Aramis video system, confirmed this assumption. The highest level of strains was observed in HAZ material and the destruction process occurred also in HAZ of the conventional welded joint.
\end{abstract}

Keywords: High-Strength Steel, Laser Welded Joints, Tensile Properties, Fracture Toughness

\section{INTRODUCTION}

With the development of steel production technology on the market appear high-strength ferritic steels, which yield strength reaches $1000 \mathrm{MPa}$. The weldability pays an important role in a broad applicability of the high-strength steels. The selection of the appropriate method and welding parameters has an influence on the quality of the resulting joints. The aim of making the welded joints is to obtain level of strength characteristics, which is not lower than in the base material (BM). It is a difficult task when high-strength steels are welded, because the welding process causes changes in the original microstructure, which may lead to a reduction of the mechanical properties of the base material in zones near the weld - in the heat affect zone (Dzioba and Pała, 2011; Hakansson, 2002; Keehan et al., 2010; LambertPerlade et al., 2010; Lillemae et al., 2016; Lisiecki, 2014; Liu et al., 2015; Mazanek et al., 2013). Thus, making a welded joint of high-strength ferritic steels, one may pay attention to quality and strength of the weld material (WM) and also to the material of heat affect zone (HAZ).

Two welded joints were tested in the research: joint made by a traditional conventional type of welding and the joint welded by an advanced laser technology. The high-strength ferritic steel S960QC was used as a base material for both welded joints (Tab. 1). Both material strength and fracture toughness characteristics of different welded joints zones were determined. Based on these results was assessed a zone, in which failure would happened. This prevision was verified during tensile test of the welded joints, in which were analyzed strain distributions obtained by using of the Aramis video systems (Aramis v6.1).

\section{TEST METHODS AND RESULTS}

The authors of the paper did not participate in the development of the welding technologies. They performed the studies on the supplied joints only. The thickness of the two type welded plates was identical $-6 \mathrm{~mm}$. However, it is an important notice, that the linear welding energy (LWE) for laser welding is significantly lower (LWE $=0.175 \mathrm{~kJ} / \mathrm{mm})$, in comparison with the traditional MIG/MAG technology $(\mathrm{LWE}=0.7 \mathrm{~kJ} / \mathrm{mm})$.

The standard test procedures were used for determination of the hardness distributions, mechanical properties and fracture toughness of the material in different zones of both welded joints (ASTM E 1820-05; PN-EN ISO 6507-1:2006, PN-EN ISO 68921:2010). The details of cut out and preparation the specimens for tensile and fracture toughness tests were presented in the paper [6]. The principle of measuring the fields of the strains by using the Aramis video system is described in the user manual (Aramis v6.1) and was presented in Pała et al. (2016).

The high level of strength properties of S960QC steel are reached using the control heat-rolling treatment during a production process. The tensile characteristics of the S960QC steel according to the standard are: $R_{\mathrm{e}} \geq 960 \mathrm{MPa}, R_{\mathrm{m}} \geq 1000 \mathrm{MPa}$ (Dzioba et al., 2014). The chemical composition is presented in the Tab. 1.

Tab. 1. Chemical composition (in wt.\%) [5]

\begin{tabular}{|c|c|c|c|c|c|c|c|c|c|c|c|}
\hline & $\mathbf{C}$ & $\mathbf{S i}$ & $\mathbf{M n}$ & $\mathbf{P}$ & $\mathbf{S}$ & $\mathbf{T i}$ & $\mathbf{C r}$ & $\mathbf{N i}$ & $\mathbf{M o}$ & $\mathbf{V}$ & $\mathbf{C u}$ \\
\hline $\begin{array}{c}\text { S960- } \\
\text { QC }\end{array}$ & 0.11 & 0.25 & 1.20 & 0.020 & 0.010 & 0.07 & $\begin{array}{c}\mathrm{CEV}=\mathrm{C}+\mathrm{Mn} / 6+(\mathrm{Cr}+\mathrm{Mo}+ \\
\text { V/5+ }\end{array}$ \\
\hline
\end{tabular}




\subsection{Hardness distributions}

Hardness measurements were carried out on the hardness tester of Wolpert Wilson Instruments Company, according to the Vicker's method with a load of $10 \mathrm{~N}$. Hardness distributions in welded joints were determined in the cross-sections of the welded plates (Fig. 1, Fig. 2). The point " $0 \mathrm{~mm}$ " on the horizontal axis corresponds to hardness of a weld material in its axis. From the hardness distribution graphs, as it can be seen that the laser joint of LWE $=0.175 \mathrm{~kJ} / \mathrm{mm}$ (Fig. 1) has a narrower weld and heat affected zone (HAZ) than the conventional joint of LWE $=0.7$ $\mathrm{kJ} / \mathrm{mm}$ (Fig. 2). In the cross-section of the laser joint, width of the weld material area and heat affected zone decreases with an increase of the distance from the weld face. Weld shape is symmetrical. From the weld face has a width of $\sim 2 \mathrm{~mm}$ and HAZ $\sim 0.7$ $\mathrm{mm}$. Then, in the middle part of thickness of smelting, is greatly reduced to $\sim 1 \mathrm{~mm}$ and a constant width $\mathrm{HAZ}$, reaching around the root, the width of $\sim 0.4 \mathrm{~mm}$ and $\mathrm{HAZ} \sim 0.3$.

a)

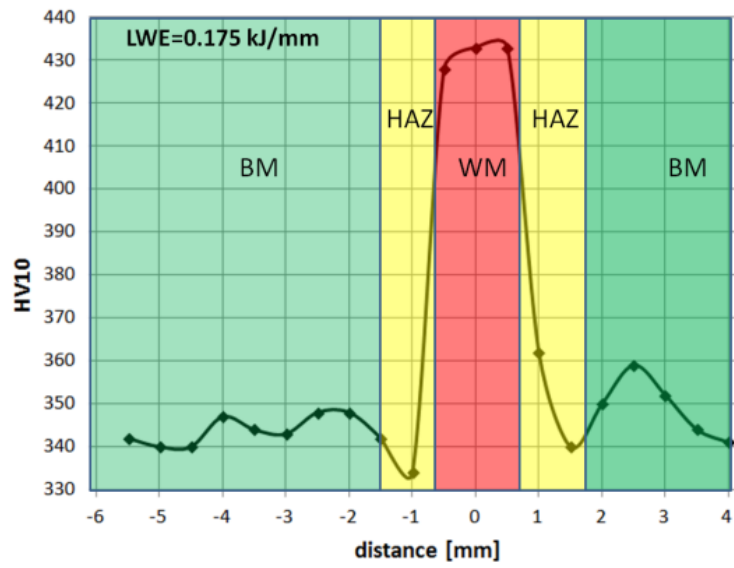

b)

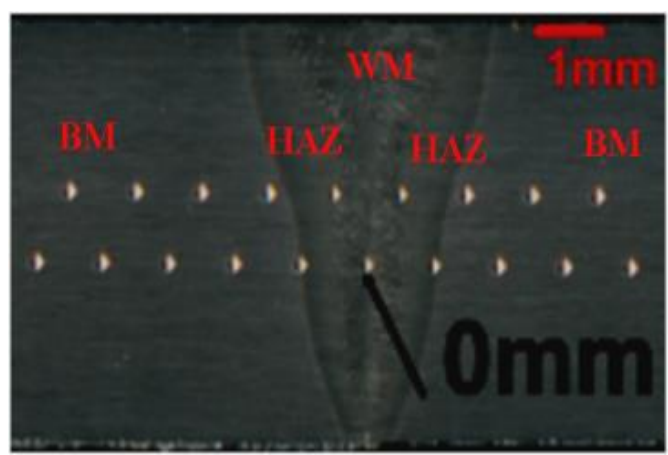

Fig. 1. The hardness distribution (a) and cross-section

(b) the laser welded joint

In the case of the joint of $L W E=0.7 \mathrm{~kJ} / \mathrm{mm}$ the weld material and $\mathrm{HAZ}$ take more complex shapes and larger sizes (Fig. 2b). At the weld face has a width of $\sim 9 \mathrm{~mm}$ and $\mathrm{HAZ} \sim 1 \mathrm{~mm}$, then there is a local narrowing. In the middle part of the weld, thickness has a width of $\sim 7 \mathrm{~mm}, \mathrm{HAZ} \sim 4 \mathrm{~mm}$. At a distance of $\sim 1.7 \mathrm{~mm}$ from the surface to the side of the root joint, the zones are narrowing to the equal value of $\sim 4 \mathrm{~mm}$ to finally reach the width of $\sim 6$ $\mathrm{mm}$ and $\sim 2.4 \mathrm{~mm}$ on the joint surface, respectively for the weld and HAZ.

From hardness distribution graphs (Fig. 1a), one may observe that hardness in the weld material in the laser joint ( $435 \mathrm{HV} 10)$ and in the welded joint by a conventional method (Fig. 2a) $(\sim 400$
HV10) are higher than the values that the base material has ( 350-370 HV10). However, the conventionally welded joint is characterized by a significant reduction in hardness in the $\mathrm{HAZ}$, of about $35-40 \%$ compared to the base material. This is a disadvantage, because one may expect that it will be an area of reduced strength properties. In the case of the laser joint, the local reduction of hardness does not occur.

a)

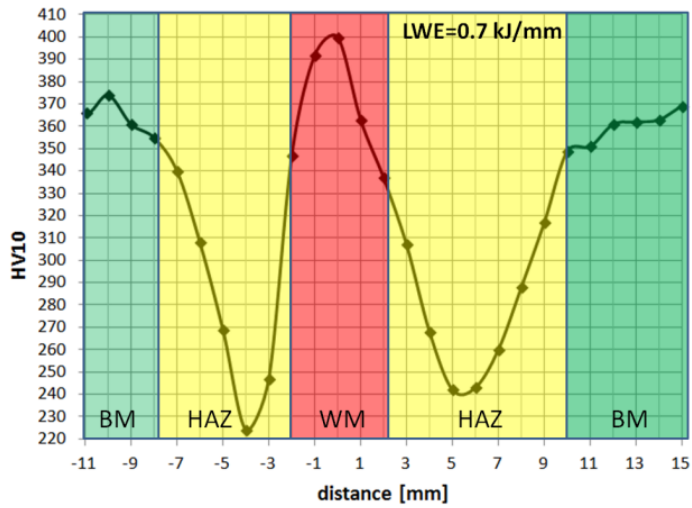

b)

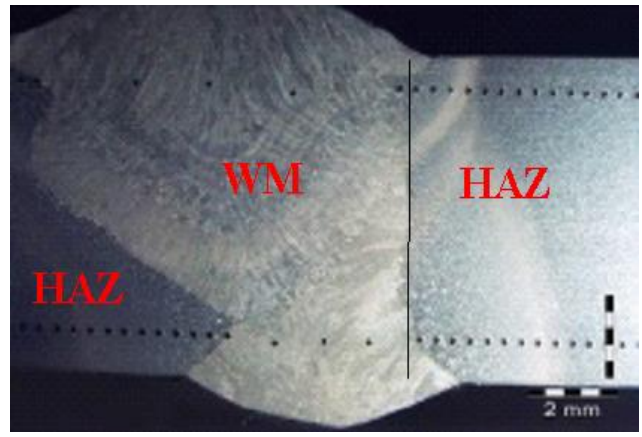

Fig. 2. The hardness distribution (a) and cross-section

(b) the conventional welded joint

\subsection{Strength properties}

Strength properties of the analyzed welded joints were determined in the uniaxial tensile test on the modernized tensile testing machine UTS-100, equipped with a test control and results record system. Signal strength and elongation of the measuring part of the specimens were recorded during carried out uniaxial tensile tests. Flat type specimens were taken from the proper areas of the welded joints: weld material (WM), heat affected zone material (HAZ) and base material (BM) [6]. The obtained results of the yield strength $\left(R_{\mathrm{e}}\right)$, ultimate strength $\left(R_{\mathrm{m}}\right)$, hardness (HV10) and Young modulus $(E)$ for both joints are presented in the Table 2. For the laser joint the mechanical properties were determined in the middle part of the HAZ material, because to the small sizes of the HAZ zone. In the case of the joint made by the conventional method the width of the $H A Z$ zone is bigger, the specimens were taken from three areas: HAZFL (in the vicinity of the fusion line), HAZN (in the vicinity of end normalization area of the material) and HAZE (near the end of the HAZ. The specimens taken from particular zones of the conventional joint to determine strength characteristics had the cross-section of $2 \times 4 \mathrm{~mm}^{2}$.

The weld material in the laser joint has very high strength characteristics: $R_{e}=1071 \mathrm{MPa}, R_{m}=1358 \mathrm{MPa}$ and hardness of $448 \mathrm{HV} 10$. In HAZ the tensile properties and hardness of the material decrease evenly to level, which corresponds to the char- 
acteristics of the base material. Analyzing setting of the true tensile curves for the particular laser joint zones, one can observe that the lowest is situated the curve representing the specimen taken from the BM (Fig. 3a). It is an advantageous situation, because the joint welded by laser can provide a loading equal to the element made of BM.

Tab. 2. Mechanical properties of the materials taken from the areas of the welded joints

\begin{tabular}{|c|c|c|c|c|c|c|c|}
\hline \multicolumn{2}{|c|}{} & \multicolumn{2}{|c|}{$\begin{array}{c}\text { LWE }=0.175 \\
\mathrm{JJ} / \mathrm{mm}\end{array}$} & \multicolumn{4}{c|}{ LWE =0.7 kJ/mm } \\
\hline $\begin{array}{c}\text { Joint } \\
\text { zone }\end{array}$ & BM & WM & HAZ & WM & HAZFL & HAZN & HAZE \\
\hline $\begin{array}{c}E, \\
(\mathrm{GPa})\end{array}$ & 185 & 193 & 192 & 178 & 187 & 185 & 191 \\
\hline $\begin{array}{c}R_{\mathrm{e}}, \\
(\mathrm{MPa})\end{array}$ & 1005 & 1071 & 1014 & 850 & 678 & 963 & 1183 \\
\hline $\begin{array}{c}R_{\mathrm{m}}, \\
(\mathrm{MPa})\end{array}$ & 1090 & 1358 & 1056 & 1090 & 912 & 975 & 1208 \\
\hline $\mathrm{HV} 10$ & 350 & 448 & 355 & 368 & 306 & 294 & 371 \\
\hline
\end{tabular}

In the conventional joint the lowest tensile characteristics occur in the HAZFL: $R_{\mathrm{e}}=678 \mathrm{MPa}$ and $R_{\mathrm{m}}=912 \mathrm{MPa}$. Also, lower than in BM tensile characteristics are in HAZN: $R_{e}=963 \mathrm{MPa}$ and $R_{\mathrm{m}}=978 \mathrm{MPa}$. The true tensile curve for specimens taken from the HAZ material sets significantly lower, than the one for BM (Fig. $3 b)$. This is a disadvantageous situation, because the welded joint is not able to provide the loading on the BM level. a)

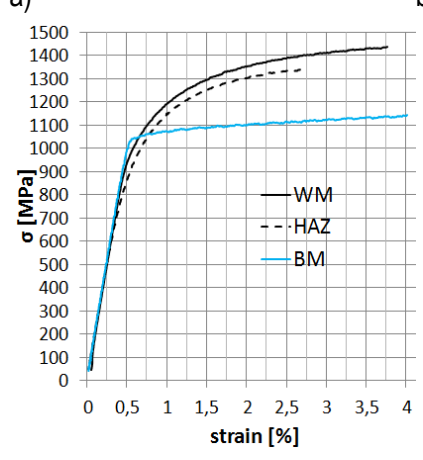

b)

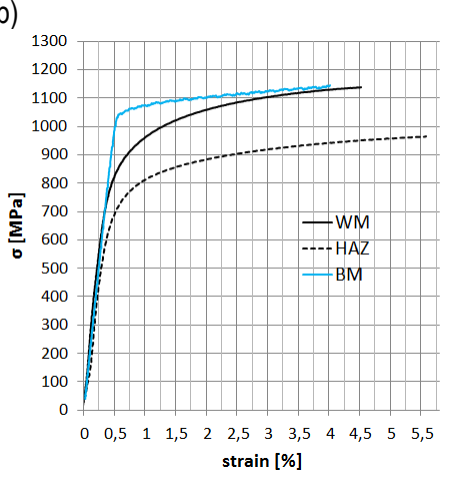

Fig. 3. The true tensile curves for the particular zones of the joint $\mathrm{LWE}=0.175 \mathrm{~kJ} / \mathrm{mm}(\mathrm{a})$ and $\mathrm{LWE}=0.7 \mathrm{~kJ} / \mathrm{mm}(\mathrm{b})$

\subsection{Fracture toughness}

Fracture toughness characteristics were determined on the MTS-250 testing machine, equipped with an automated test control and results record system. The tests were carried out at room temperature on the three point bend specimens with a single-edge notch that were mechanically cut in the WM, HAZ and BM. During fracture toughness determination the signals of force, $P$, sample bending at a load point, $U_{\text {ext, }}$ crack opening, $U_{C O D}$, and change potential, $U$, at time were recorded. In a case of ductile extension of crack fracture toughness critical values were determined according to the ASTM E1820-05 standard [2]. In the case of brittle fracture, preceded by plasticizing of the area at front of the crack, the critical values of $J_{I C}$ were calculated by the formula:
$J_{I C}=\frac{2 A_{C}}{B\left(W-a_{0}\right)}$

where: $A_{c}$ - strain energy at the moment of cracking, computed on the basis of $P=f\left(u_{\text {ext }}\right)$ graph, $W$ - specimen height, $B$ - specimen thickness, $a_{0} \approx 0.5 \mathrm{~W}$.

Critical values of $\mathrm{J}$ integral, $J_{c}$, were converted into units of stress intensity factor according to:

$K_{J C}=\sqrt{\frac{J_{I C} E}{\left(1-v^{2}\right)}}$

where: $E$ - Young's modulus, $v$ - Poisson's ratio.

The critical values of fracture toughness for the laser joints and the joints welded by a conventional method are presented in the Table 3. The fracture toughness critical values were determined in WM, HAZ and BM. Next, in the HAZ area the values of the $K_{\mathrm{Jc}}$ were determined in three locations: HAZFL - vicinity of the fusion line; HAZ_ 0.5 - at the distance $0.5 \mathrm{~mm}$ from a fusion line; HAZN - in the vicinity of end the normalization area. A sample specimen of notched in the weld material for the laser joint presented in the Fig. 4.

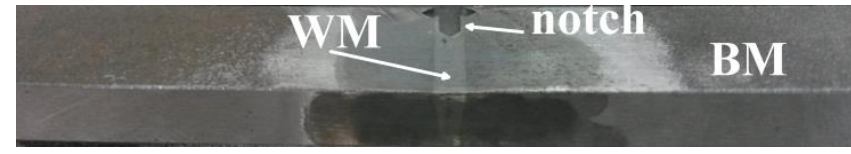

Fig. 4. A sample specimen notched in the laser weld material

Tab. 3. Fracture toughness in the zones of the laser and conventional joint

\begin{tabular}{|c|c|c|c|c|c|}
\hline & \multicolumn{5}{|c|}{ Joint zones } \\
\cline { 2 - 6 } & WM & HAZFL & HAZ_05 & HAZN & BM \\
\hline \multicolumn{5}{|c|}{ Conventional joint (LWE $0.7 \mathrm{~kJ} / \mathrm{mm})$} \\
\hline $\begin{array}{c}K_{\mathrm{JC}} \\
{\left[\mathrm{MPa}^{*} \mathrm{~m}^{1 / 2}\right]}\end{array}$ & $155 ; 160$ & $168 ; 188$ & $\begin{array}{c}160 ; 170 ; \\
260\end{array}$ & $290 ; 310$ & $\mathbf{2 6 0} 2280$ \\
\hline \multicolumn{5}{|c|}{ Laser joint (LWE $=0.175 \mathrm{~kJ} / \mathrm{mm})$} \\
\hline $\begin{array}{c}K_{\mathrm{JC}} \\
{\left[\mathrm{MPa}^{*} \mathrm{~m}^{1 / 2}\right]}\end{array}$ & $159 ; 162$ & $152 ; 159$ & $\mathbf{2 4 4} ; 250$ & $\mathbf{2 9 7} ; 299$ & $\mathbf{2 6 9} ; 288$ \\
\hline
\end{tabular}

The lowest values of the fracture toughness for both welded joints were obtained for the WM. For conventional welded joints was observed the level $K_{\mathrm{Jc}}$ similar to WM for the material of the HAZFL and HAZ_0.5. An increase of the distance from a fusion line leads to an increase of the material fracture toughness values to the level proper for the BM. For laser welded joints the level $K_{\mathrm{JC}}$ similar to WM was obtained only in HAZFL area. In the areas more away from the fusion line, the fracture toughness reaches the level similar for BM. Base on these results we can state, that laser joints have higher fracture toughness in comparison to joints welded conventionally.

\subsection{The microstructure studies of the welded joints material}

The base material, steel $5960 \mathrm{C}$, as a result of the thermomechanical treatment performed in a controlled manner directly at the production line, has a fine-grained bainite-martensite microstructure (Fig. 5) and a high level of tensile properties and fracture toughness that were shown above. The obtained results are confirmed with data received for similar steels, which has fine-grained bainite-martensite microstructure (Bhadeshia, 2001; Dzioba, 2011). 
As a welding result the weld material has of martensitebainite types (Fig. 6) with small laths of $0.5-2.0 \mathrm{~mm}$ width. The increase of LWE level is caused by more numerous and larger carbide precipitates which are occurred in WM.

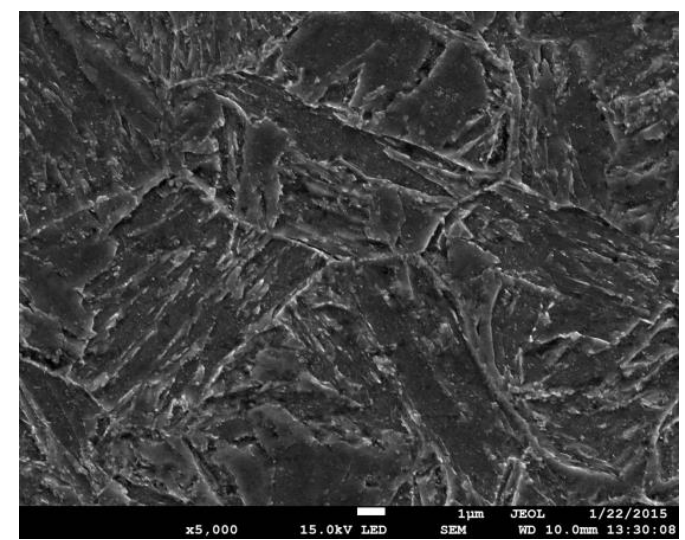

Fig. 5. Bainite-martensite microstructure of the $S 960 \mathrm{QC}$ steel

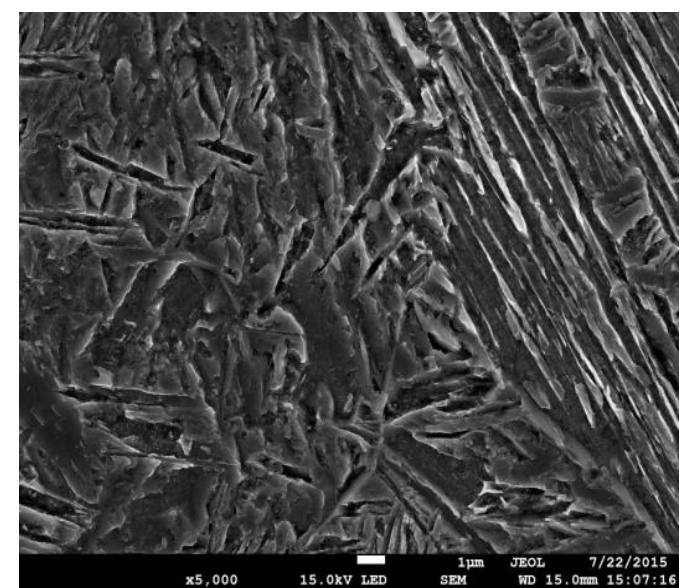

Fig. 6. Martensite-bainite microstructure the WM of the joints

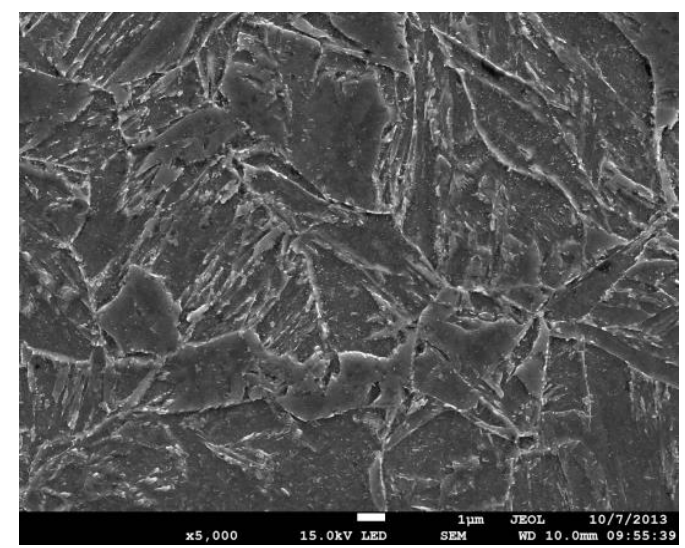

Fig. 7. Bainite-martensite microstructure in the $H A Z$ of the joint welded with LWE $=0.175 \mathrm{~kJ} / \mathrm{mm}$

The significant differences in types of microstructure are observed in HAZ. The welding process made with lower LWE level has an insignificant influence on the microstructure of a base material. Only more numerous carbide precipitates in comparison to $\mathrm{BM}$ were observed in $\mathrm{HAZ}$ after welding with $\mathrm{LWE}=0.175 \mathrm{~kJ} / \mathrm{mm}$ (Fig. 7). The welding with a high level of
LWE lead to significant changes in the microstructure of BM. As a result welding with $L W E=0.7 \mathrm{~kJ} / \mathrm{mm}$ in $\mathrm{HAZ}$ is observed finegrained ferrite microstructure with numerous carbide precipitates (Fig. 8). This type of microstructure is characterized by a lower level of tensile and fracture toughness properties (Bhadeshia, 2001; Dzioba, 2011; Lambert-Perlade et al., 2004; Tweed and Knott, 1987; Yang et al., 2015).

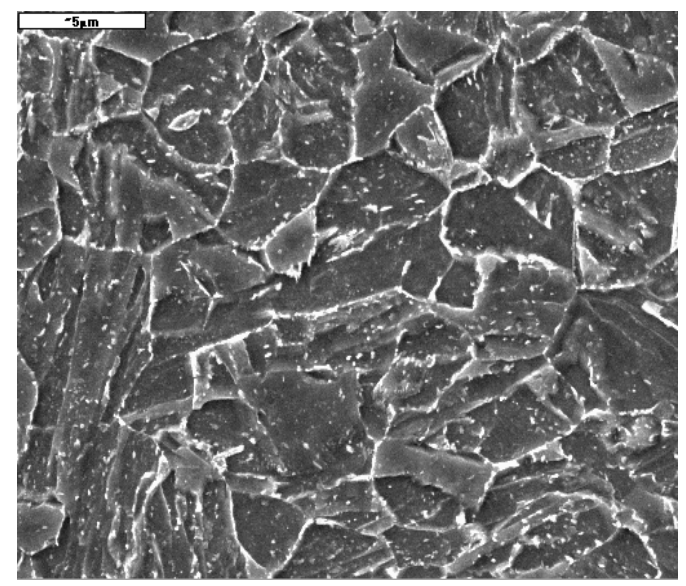

Fig. 8. The fine-grain ferrite with carbides precipitates microstructure in the HAZ of the joint welded with LWE $=0.7 \mathrm{~kJ} / \mathrm{mm}$

\subsection{Uniaxial loading the welded joints carried out by using the Aramis video system}

In the next stage was performed verification of the joints strength. The flat specimens, which contained welded joints were loaded by uniaxial tensile. The verification was done on the base results from the strain maps obtained using the Aramis video system. The strain maps on the surface loaded element measured were received in current time by using the video system.

a)

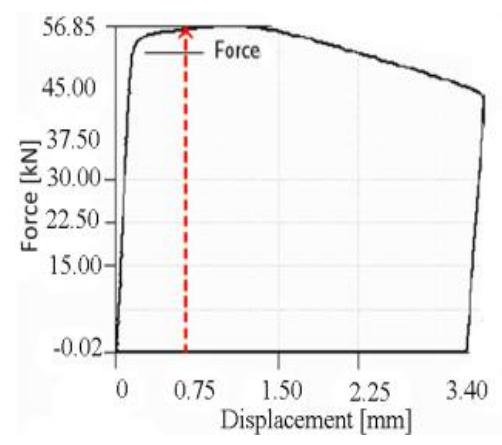

b)

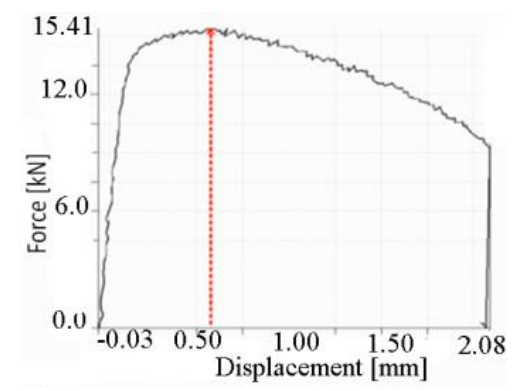

Fig. 9. Plots of force-displacement for a laser (a) and conventional (b) joints 
In the Fig. 9a and 9b are shown the force-displacement curves recorded during uniaxial tensile loading of the welded joints. The strain maps, which correspond to the maximum loading, for the laser joint and the conventional joint, are presented in figures 10a and 10b. At following loading in the laser welded joint the region, where the maximal strain occurs and creating a neck, performed in the BM, which means that the BM is the weakest in this welded joint. In the conventional joint, by contrast, the weakest area exposed in HAZ. Following loading leaded to destruction in the corresponding areas of the joints. The results obtained by using the Aramis video system confirm the results of strength and fracture toughness properties of the material from different zones the welded joints.

a)

b)
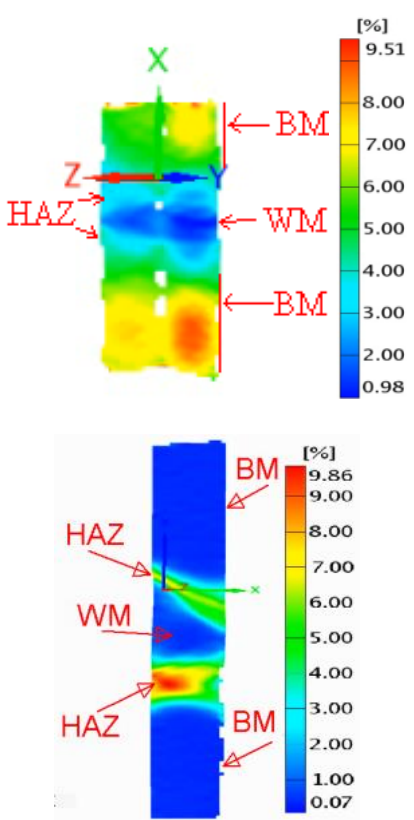

Fig. 10. The corresponding strain maps at the moment of acting of the maximum load for a laser (a) and conventional (b) joints, respectively

\section{CONCLUSION}

The presented study clearly shows that the laser joints of high-strength steel S960QC have more advantageous mechanical properties, than joints welded by the conventional technology. The geometry sizes of laser welded joints are less than ones made of conventional technology. In the laser welded joints reduction hardness and tensile properties in WM and HAZ of the laser welded joints does not occur, as opposed to the joints conventionally welded. The fracture toughness the material in different areas of the laser welded joints is no less than in the conventional joints.

Verification tests carried out for the both welded joints by using the Aramis video system validated previous assumption according to the weakness areas in the welded joints. In the conventional welded joints the weakness area is the HAZ, what is not advantageous, because the mechanical properties in the HAZ are lower than of the BM, so the joint is not able to resists load such as the BM. In the laser welded joints the weakness area is the $\mathrm{BM}$, what is favorable, because the joint is able to resist load as the BM.

\section{REFERENCES}

1. Aramis v6.1 User Manual, GOM Gmbh, 2009 .

2. ASTM E 1820-05, Standard Test Method for Measurement of Fracture Toughnes,. ASTM, Philadelphia; 2000.

3. Bhadeshia H.K.D.H. (2001), Bainite in Steels, Institute of Materials, London.

4. Dzioba I. (2011), The influence of the microstructural components on fracture toughness of 13HMF steel, Materials Science, 47(5), 357364.

5. Dzioba I., Pała T. (2014), Mechanical properties of welded joints made of high-strength steel $\mathrm{S} 960-\mathrm{QC}$ by laser method, Logistyka, 6 , 3458-3464 (in Polish).

6. Dzioba I., Pała T., Valkonen I. (2013), Strength and fracture toughness of the welded joints made of high-strength ferritic steel, Acta Mechanica et Automatica, 7(4), 226-229.

7. Gałkiewicz J., Pała T., Dzioba I. (2012), Mechanical properties of the welded joints of ultra-strength ferritic steels, XXIII Symposium on Fatigue and Fracture Mechanics Bydgoszcz- Pieczyska, 63-72 (in Polish).

8. Górka J. (2015), Weldability of Thermomechanically Treated Steels Having a High Yield Point, Archives of Metallurgy and Materials, 60(1), 469-475.

9. Hakansson K., Weld Metal Properties for Extra High Strength Steels, Report 2002 - August, Division of Welding, Department of Production Engineering, The Royal Institute of Technology, 1-36.

10. Keehan E., Zachrisson J., Karlsson L. (2010), Influence of cooling rate on microstructure and properties of high strength steel weld metal, Science and Technology of Welding and Joining, 15, 233-238.

11. Lambert-Perlade A., Gourgues A.F., Besson J., Sturel T., Pineau A. (2004), Mechanisms and modeling of cleavage fracture in simulated heat-affected zone microstructures of a high-strength low alloy steel, Metall Mater Trans A; 35(13):1039-53.

12. Lillemäe I., Remes H., Liinalampi S., Itävuo A. (2016), Influence of weld quality on the fatigue strength of thin normal and high strength steel butt joints, Welding in the World, 4, 1-10.

13. Lisiecki A. (2014), Weldability of Thermomechanically Treated Steels Having a High Yield Point, Archives of Metallurgy and Materials, 59(4), 1625-1631.

14. Liu F., Yu X., Huang C., He L., Chen Y., Bu W. (2015), Microstructure and mechanical properties of AerMet 100 ultra-high strength steel joints by laser welding, Journal of Wuhan University of Technology-Mater. Sci. Ed., 8/2015, 30, 827-830.

15. Mazanek K., Sniezek I., Slezak T. (2013), Fatigue research of welded joints of high strength $\mathrm{S} 960 \mathrm{QL}$ steel, Bulletin of the Military University of Technology, 42(1), 253-269 (in Polish).

16. Pała T., Gałkiewicz J., Dzioba I. (2016), Determination of Strain and Stress Fields in Laser Welded Joints by Means of the Aramis Video System, Solid State Phenomena, 250, 151-156.

17. PN-EN ISO 6507-1:2006. Metals, toughness measurement by the Vicker's method, part 1, testing method (in Polish).

18. PN-EN ISO 6892-1:2010. Metals, tensile test, part 1: Testing method at room temperature (in Polish).

19. Tweed J.R., Knott J.F. (1987), Micromechanisms of failure in C-Mn weld metal, Acta Metallurgica, 35(7), 1401-1414.

20. Yang Y., Shi L., Xu Z., Lu H., Chen X., Wang X. (2015), Fracture toughness of the materials in welded joints of $X 80$ pipeline steel, Engineering Fracture Mechanics, 148, 337-349.

Acknowledgments: Financial support from the Grant of the Polish National Centrum of Research and Development (NCBiR) PBS1/B5/13/2012 and the Polish Ministry of Science and Higher Education under contracts NN 01.0.08.00/2.01.01.01.0035 are gratefully acknowledged. 